\title{
O RELACIONAMENTO DO IDOSO COM OS SEUS FAMULIARES
}

Alcinéa Eustáquia Costa* Lélia Maria Madeira*

COSTA, A. E.; MADEIRA, L. M. O relacionamento do idoso com os seus familiares. Rev.

Esc. Enf. USP,v.28, n.1, p. 83-95, abril, 1994.

Estudo exploratório-descritivo com os objetivos de conhecer o relacionamento interpessoal entre o idoso e seus familiares e verificar a percepçāo deste sobre o processo de envelhecimento. Foram entrevistadas 20 pessoas (10 homens e 10 mulheres) acima de 60 anos. Os resultados encontrados, provavelmente subsidiarảo a assistência de enfermagem a pessoas nessa faixa etária.

UNITERMOS: Idosos. Relaçöes interpessoais.

\section{INTRODUÇĀO}

A expressāo "relacionamento" engloba em seu significado as relaçōes do homem com os seus semelhantes pelo processo de comunicaçāo verbal e não verbal.

O relacionamento família/idoso tem correlação direta com o processo de comunicação interpessoal entre seus integrantes.

A literatura sobre Comunicação é muito vasta, podendo-se encontrar estudos em várias especialidades da área de saúde, dado o caráter "multifacetário" do processo de comunicaçăo no relacionamento interpessoal.

$\mathrm{Na}$ enfermagem o assunto, comunicaçāo, tem merecido a atenção de vários estudiosos, em especial sob o enfoque do relacionamento interpessoal. Todavia, no que diz respeito à forma de comunicação entre enfermagem/idoso/família, a bibliografia é escassa.

Esta escassez de estudos provavelmente se deve ao fato de que só recentemente a atenção da sociedade tem-se voltado para os indivíduos da terceira idade. A política nacional de assistência à saúde do idoso é recente e ainda predomina a assistência do médico geriatra; os idosos saudáveis em geral ficam aos cuidados da família ou em uma instituiçāo "asilar". A participação da enfermeira ainda não se destaca na assistência a este grupo etário.

- Enfermeira. Docentes da Escola de Enfermagem da Universidade Federal de Minas Gerais. 
JORDÄO-NETTO ${ }^{10}$ informa que recentemente foi criada a Associação Nacional de Geriatria e Gerontologia, de caráter multidisciplinar, portanto, com a participação do enfermeiro, cabendo aos gerontólogos a assistência à saúde mental, além de alguns cuidados físicos aos idosos.

A assistência à saúde mental do indivíduo da terceira idade, que constitui uma das preocupaçōes dos enfermeiros, coloca em primeiro plano as questōes relativas ao processo de comunicação das pessoas dessa faixa etária.

Para MORAN ${ }^{13}$, "a comunicação é um complexo de interaçōes em vários níveis (do interpessoal ao social) que viabiliza e expressa vários processos e níveis de troca simbólica de sistemas de significação, de veiculação ideológica dentro do universo cultural. A comunicação mostra e expressa relaçōes entre grupos, classes, instituiçōes; interliga o tecido social, a trama das relaçóes humanas, dinamizando e significando essas relaçöes."

Reforça-se, assim, a idéia de que a problemática da comunicação na terceira idade não é simplesmente decorrente dos aspectos, cultural e emocional, da família, e sim do contexto mais amplo que é o político, econômico e cultural de uma sociedade.

FRAIMAN ${ }^{6}$ adverte que a educação e a comunicação, em seus primórdios, eram mais orientadas para a filosofia, uma sabedoria transmissivel, que significa uma construção mental lógico-existencial com base no diálogo. Igualmente AGUIRRE ${ }^{1}$ diz que, em várias culturas mais antigas, a terceira idade era caracterizada como um período da vida de maior serenidade e dignidade, reconhecido por todos os que ainda näo haviam adquirido, a precisa experiência e sabedoria dos mais longevos. Nesse contexto o idoso contribuía com o que a vida lhe permitira aprender.

VIETTA; CARVALHO ${ }^{16}$ declararam que, de modo geral, a linguagem pode ser entendida como um sistema de sinais que permitem aos seres humanos comunicar-se entre si. Estas autoras afirmam que na tentativa de garantir o equilibrio de seu mundo interior, os individuos procuram manipular o meio externo de forma que não lhe seja exigido o que poderia ser, mas onde possa se acomodar tal como está sendo, sem esforço adaptativo.

Na visảo de MYERSCOUGH ${ }^{14}$, na terceira idade, pode ocorrer a aparente acomodaçāo decorrente da autopercepção do idoso nesta fase e que leva alguns a perceberem fatos e acontecimentos de formas diferentes: dinheiro, transportes, comunicaçōes, jornais, comportamento público e privado.

Esta aparente acomodaçào decorre dos aspectos normais da senescência os quais, para DREHER ${ }^{5}$, constituem barreiras de comunicaçāo que funcionam em maior ou menor grau conforme o ambiente familiar do indivíduo.

Pode-se acentuar que a assistência à saúde mental deve estar assentada na dignidade do ser humano. Na visảo de LANGARICA ${ }^{11}$, os idosos têm as mesmas necessidades dos mais jovens. Em geral, as pessoas mais jovens 
associam o envelhecimento à doença chegando a considerarem como sinônimos.

As reaçōes à velhice são diferentes em cada pessoa, devido à individualidade do ser humano; decorre, especialmente, do ambiente familiar em que este é inserido, e de determinantes sócio-culturais.

JORDÄO-NETTO ${ }^{8}$ pondera que as relaçōes idoso e família sofreram, através dos tempos muitas mudanças, acompanhando as próprias transformaçōes experimentadas pela instituiçāo família.

Em que pesem as mudanças sócio-culturais e as conseqüentes mudanças estruturais na vida do indivíduo, nenhuma instituição substitui a família no cuidado à pessoa da terceira idade; daí a importância de se estudar a comunicação do idoso, no seu contexto familiar, e a dos membros da família com o idoso.

Em decorrência do argumento acima referido, levantam-se as seguintes questōes a serem investigadas:

- Quais as principais dificuldades de relacionamento entre o idoso e seus familiares?

- Como superar barreiras da comunicação, do ponto de vista do idoso?

- O que significa envelhecer, para o idoso?

Estas questōes foram formuladas partindo do princípio de que existem dificuldades de relacionamento do idoso com os seus familiares, decorrentes dos fatores inerentes à senescência. FRAIMAN" ${ }^{8}$ afirma que "mesmo os idosos que vivem no seio de sua familia, cercados por atençōes e cuidados que esta lhes dispensa, muitas vezes se referem a um estado de inadaptação e vazio interior, que os próprios familiares e amigos não conseguem compreender". Esta situação segundo este autor pode acarretar problemas para o idoso, como o isolamento da pessoa idosa pelos familiares e também seu afastamento dos familiares. $O$ isolamento é geralmente caracterizado como mecanismo de defesa de ambas as partes, isto é, do idoso e de seu familiar, a fim de que seja evitado o "stress" na interação.

Com o propósito de clarear essas dificuldades, que poderá ajudar o idoso e familiares a compreenderem as barreiras de comunicação na senescência e, conseqüentemente, contribuir para melhor relacionamento interpessoal na terceira idade, propuseram-se os seguintes objetivos para este estudo:

- Conhecer o relacionamento interpessoal entre o idoso e seus familiares;

- Verificar a percepção do idoso sobre o processo de envelhecimento. 
Foi realizado um estudo exploratório-descritivo, com idosos residentes em Belo Horizonte.

A população do estudo foi constituída por pais de professores da Escola de Enfermagem da Universidade Federal de Minas Gerais (UFMG) e a amostra foi delimitada por pessoas de idade superior a 60 anos, que são classificadas como estando na terceira idade. A amostra totalizou 10 pessoas do sexo masculino e 10 do sexo feminino.

Para delimitação da amostra realizou-se um levantamento prévio de docentes cujos pais atendiam aos critérios estabelecidos e concordariam em participar do estudo.

Posteriormente, realizaram-8e entrevistas semi-estruturadas (ANEXO I), feitas através de visitas dos pesquisadores às residências dos idosos, integrantes da população.

\section{APRESENTAÇĀO E ANÁLISE DOS RESULTADOS}

Os idosos pesquisados foram caracterizados quanto ao sexo, idade e grau de instrução (ANEXO II). Sobre a idade, os de sexo masculino encontravam-se na faixa etária dos 60 a 75 anos, sendo que apenas um já tinha completado 80 anos. As mulheres estavam na faixa etária de 60 a 75 anos havendo predomínio daquelas da faixa de 60 a 65 anos (5 mulheres: 50,0\%).

O predomínio de esposas mais jovens que os maridos na populaçāo idosa é confirmado por BERQUO; LEITE 2; estes afirmam que normas sociais e culturais prevalentes em nossa sociedade levam os homens a se casarem com mulheres mais jovens que eles.

Quanto ao grau de instrução, o percentual foi o mesmo entre homens e mulheres com curso primário $(50,0 \%)$. Por outro lado, verificou-se $30,0 \%$ de homens com curso superior e nenhuma mulher.

No estudo citado anteriormente por BERQUO; LEITE ${ }^{2}$, os dados censitários de 1980 sobre a população idosa demonstraram haver mais analfabetos na população idosa do que na populaçāo total; daqueles que conseguiram chegar às escolas, apenas $50,4 \%$ completaram o curso primário.

A situação econômica da amostra estudada é mais ou menos homogênea e poder-se-ia classificá-la como de classe média. Daí o fato de não se ter encontrado nenhum analfabeto e constatado a presença de homens até com curso superior. A amostra citada demonstra que a escolaridade dos idosos de hoje reflete as condiçōes sociais de um período histórico que remonta ao início do século. Trata-se de uma época em que as chances de acesso à educação eram extremamente diferentes das de hoje, pois privilegiavam as elites $e$, nelas, mais os homens do que as mulheres.

Numa tentativa de conhecer o relacionamento interpessoal entre o idoso e seus familiares, foram feitas as 4 (quatro) primeiras perguntas, cujas respostas serão apresentadas a seguir. 
Pergunta: "Com quem se dá melhor em sua família?"

Trinta por cento $(30,0 \%)$ dos homens e $10,0 \%$ das mulheres responderam não haver nenhuma preferência dentro do grupo familiar. Entretanto, 30,0\% dos homens e 40,0\% das mulheres mencionaram dar-se melhor com as filhas, justificando-se da seguinte maneira:

"... é da área de saúde; se responsabiliza mais pela nossa assistência médica."

"... é mais comunicativa, me procura mais, me entende bastante, está sempre do meu lado para ver se preciso de alguma coisa."

"... por causa da convivência diária."

"... afinamos mais o pensamento... é mais chegada em mim, mais dependente, retribui a atenção que dou a ela."

"... nos dá mais assistência, ajuda a resolver os problemas, ... tenho mais liberdade de procurar, de telefonar."

Outras preferências mencionadas recaem sobre o cônjuge, irmāos, cunhada, genro e amigos.

Pergunta: "Com quem se dá pior?", Cincoenta por cento das mulheres e 40,0\% dos homens näo destacaram nenhuma pessoa com quem se dessem pior. Estes dados, associados a expressöes não-verbais de alguns respondentes, sugerem a dificuldade que algumas pessoas sentem para apontar caracteristicas negativas de outras, principalmente numa entrevista a estranhos. Todavia, daqueles que conseguiram apontar com quem se davam pior, havia predomínio de referência ao filho, tanto pelos homens $(50,0 \%)$ quanto pelas mulheres $(20,0 \%)$, conforme justificaram:

"... nāo tem responsabilidade..."

"... nâo compreende a gente, quer direcionar o que faço;"

“... nossos gênios são parecidos, somos semelhantes nos defeitos... somos dois neuróticos."

"... é o mais egoísta dos filhos."

“... me deixa muito stressada, tem gênio muito difícil, explosivo... personalidade muito difícil."

É interessante ressaltar que a faixa etária dos filhos mencionados varia de 29 a 42 anos, sendo, portanto, todos adultos.

As demais pessoas apontadas pelos idosos como de pior convivência referem-se a filhas, irmãos e cônjuge.

O fato das mulheres terem sido apontadas como de melhor relacionamento parece vincular-se ao seu papel socialmente reconhecido como "provedora de cuidados", conforme afirma COLLIERE 4 em seu estudo sobre o papel histórico da mulher.

Pergunta: "Como o Sr(a) gostaria que fosse o relacionamento entre o $\operatorname{sr}(a)$ e sua familia?"

6 respondentes - $(30,0 \%)$ disseram não ter problema de relacionamento; $7(35,0 \%)$ deram respostas que levam a pensar na satisfaçāo de suas próprias necessidades: sozinho."

“... gostaria que as pessoas entendessem que gosto de ficar 
"... gostaria que me dessem liberdade para fazer o que quero."

"... gostaria de ser mais compreensivo, mais aberto."

"... melhorar comunicação é a gente nāo se retrair..."

"... gostaria que respeitassem mais minhas opinióes."

“... ter liberdade de falar as coisas, de conversar, aceitar a gente como a gente é... aceitar as diferenças."

"... gostaria que o filho fosse mais carinboso, mais próximo da gente."

Os demais pesquisados, $7(35,5 \%)$ verbalizaram o desejo ou a necessidade de maior união familiar como forma de melhorar o relacionamento:

"... gostaria que todos fossem mais unidos..."

“... que a gente se entendesse melhor, aceitando a opiniāo deles e eles a da gente."

"... gostaria que todos estivessem mais juntos nas alegrias..."

Pelos dados apresentados, até o momento é possivel verificar o significado que a familia e familiares, em especial filhas e filhos, têm para os idosos estudados. Diversos autores abordam a importância do relacionamento familiar na terceira idade, tanto em casos de idosos sadios como de doentes. MONTGOMERY ${ }^{12}$ afirma que as relações do idoso com sua família, estando o mesmo em casa ou em uma instituição, é fato crucial para sua vida.

A capacidade de identificaçāo das dificuldades que o idoso sente para comunicar-se foi surpreendente neste estudo. Tanto homens quanto mulheres foram capazes de apontar problemas de comunicação que são originados pelo seu próprio comportamento. Em sua maioria estas dificuldades são conseqüentes à "diferenças no modo de pensar" e à "diminuição da sociabilidade", do idoso, como pode ser visto nas afirmaçōes:

“... a gente espera determinado comportamento do jovem que hoje já está ultrapagsado."

"... tem pessoas que sāo chatas, tudo está ruim, sempre se queixando..."

“... tem casos em que o idoso tem dificuldade de ser entendido pelos mais jovens."

"... sou sistemático, mais calado... às vezes é difícil as pessoas entenderem meu modo de ser."

“... quem tem dificuldade é porque nāo conseguiu mudar o pensamento; aí o jovem foge do velho e o velho foge do jovem."

"... é diferente o modo de pensar, a gente fica mais egoísta, mais embotado, preocupado consigo próprio."

"... estou mais introspectivo, menos social..."

"... muda a forma de pensar... nāo concordo com muitas coisas, penso diferente."

"... sou mais reservado, menos comunicativo; mudei muito... sou do tempo do quadrado..."

As dificuldades apontadas como sendo devido "diferenças no modo de pensar" sugeriram que estes idosos tinham problemas de relacionamento, principalmente com adolescentes, quando estas diferenças são marcantes. No 
entanto, apesar de se ter encontrado alguns casais que têm ou mesmo que convivem com netos adolescentes, estes não foram identificados nos dados coletados anteriormente, como sendo os de pior convivéncia. Por outro lado, sabe-se que as regras e valores sociais mudam muito rapidamente e, nem sempre as pessoas conseguem acompanhar essa mudança.

Segundo DREHER ${ }^{5}$, os padrōes ético-morais do idoso, ensinados na infância e reforçados na vida adulta tornam-se arraigados na velhice e, é através deles que o idoso percebe os movimentos sociais atuais. Isto provoca julgamentos negativos sobre o comportamento das pessoas, o que concorre para o nāo envolvimento e o isolamento do idoso.

Ainda em relaçāo às dificuldades de comunicação, $20,0 \%$ referem-se a problemas de deficiência física, como, por exemplo diminuiçāo de visão, audição e potência fisica, ou ao surgimento de uma doença propriamente dita. Mais mulheres $(50,0 \%)$ que homens $(20,0 \%)$ disseram não ter dificuldades de comunicar-se com os outros e algumas até ressaltam que a capacidade de comunicação melhorou com a idade.

Para conhecer a percepçāo dos idosos sobre o processo de envelhecimento foi-lhes perguntado: "o que é envelhecer?"

As respostas, agrupadas por sexo, mostram o significado da velhice para os entrevistados.

As mulheres expressaram-se sobre o processo de envelhecimento da seguinte forma:

"É experiência que a gente adquire; é encarar a vida de uma maneira diferente."

"Significa ir acabando aos poucos, devido ao cansaço geral. Ter experiência de vida e ser respeitado pelos filhos..."

"Sảo os anos que vāo paseando e a gente vai mudando. Aumenta a preocupação com a morte. Muda a fisionomia, as rugas e os cabelos brancos vão chegando."

"É uma situação que tem que acontecer mesmo. A gente tem que aceitar. É igual a morte, a gente tem que morrer mesmo."

"E uma série de coisas: doenças, incapacidade para fazer tudo que quer, lapsos de memória, deficiência auditiva... Com o envelhecimento do corpo a auto-imagem fica alterada."

"É alterar em todas as partes, corpo e mente. A gente fica mais cansada mas tem que aceitar certas coisas... aquele que está com a razāo..."

"É uma ocorrência natural. Vi que estava envelhecendo depois que aposentei..."

"E uma experiência que a gente aproveita mais depois dos 60 anos, mesmo estando doente. Depende do que acumulou na vida: paz ou tristeza..."

"Começam a aparecer as doenças... sinto não ter mais a mesma força... não tenho mais tanto interesse pela parte sexual... não tenho mais a mesma animaçāo... a alimentaçào é limitada." 
"Acho difícil falar de uma coisa que nem penso. Diria então que envelhecer é ir passando a idade..."

As verbalizaçōes sobre "o que é envelhecer" dos idosos do sexo masculino foram:

“... é a lei natural que acontece a todas as coisas e a todas as pessoas... Velho nāo é ser doente, mas se a doença vem com a idade a gente tem que aceitar... mas para aceitar a gente sofre."

"... O cabelo fica branco; a gente fica mais fraco; a vista enfraquece; a perna dói... num dia sente uma dor, noutro dia outra."

"Comparo ao desgaste de uma máquina. Cada dia aparece uma coisa diferente... é o desgaste da máquina humana."

"É uma dádiva pela pessoa ter se comportado de forma decente, de consciência tranqüila, sem desejar mal ao próximo..."

"É nāo fazer extravagâncias, controlar melhor a saúde, levar uma vida sem preocupação, entender melhor a vida, as pessoas... é ter mais tempo para as lembranças... ter mais experiências, mais paciência com os netos que teve com os filhos. Envelhecer com saúde mental e durar muito nesta vida é herança familiar."

"É a seqūência natural da vida... o homem nasce, desenvolve e morre. Velhice é a última fase do desenvolvimento humano."

"Nāo é só atingir uma idade, a gente vai modificando os pensamentos, as razóes de acordo com a idade... vai acumulando experiências e vivências... vai aceitando coisas que anteriormente nảo aceitava, fica mais compreensivo com os filhos." lia."

"É mais responsabilidade que a gente toma com a própria fami-

"É perder todas as potencialidades físicas, fisiológicas e psicológicas... gradativamente. Vai perdendo o atrativo pela vida."

"É aparecer alguma coisa como por exemplo uma artrose no joelho... $O$ relacionamento com a esposa muda... parece irmão... tem mais amor, a afeição é mais forte, mais cuidado um com o outro... a relação sexual é que muda."

A maioria dos idosos, homens ou mulheres, referem-se ao envelhecimento como "lei natural", "acúmulo de experiências" e "alteraçōes físicas", não havendo predominância de determinada concepção por sexo.

Das respostas pode-se constatar, ainda, que os pesquisadores compreendem o envelhecimento como um processo natural na vida do ser humano.

As percepções destes são semelhantes ao que é descrito por autores como: JORDÄO-NETO ${ }^{\theta}$ e HOGSTEL; KASHKA ${ }^{7}$. Estes últimos, estudando os fatores que mais contribuíam para a longevidade saudável de idosos a mericanos com mais de $\mathbf{8 5}$ anos, listaram os fatores mais mencionados:

- atividade fisica e mental;

- forte crença em Deus; 
- atitude positiva em relação a si mesmo e aos outros;

- vida equilibrada (sem drogas e sem fumo);

- boa alimentação;

- apoio familiar;

- hereditariedade;

- boa saúde ao longo da vida;

- ajuda aos outros;

- sono e repouso adequados;

- uso dos recursos dos serviços de saúde.

Outro dado que merece ser destacado é o fato de que, apesar da grande maioria dos respondentes perceberem o envelhecimento como uma lei natural da vida, poucos mencionam ou explicitam a possibilidade da morte, havendo um que até mesmo nega o envelhecimento dizendo: "acho difícil falar de uma coisa que nem penso..."

Ao final da entrevista foi dada aos entrevistados, a oportunidade de complementarem sua fala, e de fazerem qualquer declaraçāo que achassem pertinente. Os que o fizeram repetiram o discurso sobre sua percepção do que é envelhecer. Estas declaraçóes reforçam a necessidade da compreensāo da problemática relativa aos aspectos biológicos, psicológicos e sociais que envolvem o processo de envelhecimento, näo somente por aqueles que lidam com o idoso, mas por toda a sociedade.

Em face dos resultados obtidos seria pertinente refletir-se sobre as implicaçöes dos mesmos para a assistência de enfermagem.

O cuidado ao ser humano, hoje, está relacionado ao discurso sobre cidadania, o que vem de encontro à visäo holística defendida pela enfermagem.

Os dados deste trabalho provavelmente fornecerão subsídios para a enfermagem compreender o idoso, no que diz respeito tanto às suas relações familiares, quanto às suas percepçóes sobre o envelhecimento. Isto, com certeza, permitirá melhor adequação da assistência às reais necessidades dos idosos, estejam eles num ambiente familiar ou institucionalizado.

Essa assistência exige a capacidade e o desejo de compreender o idoso, como bem relata DREHER ${ }^{5}$ ao estudar o processo de comunicação com pessoas nesta faixa etária. A referida autora ressalta que, para se comunicar com pessoa na terceira idade, é necessário saber ouvir, e que isso nāo exige apenas habilidade física, mas também atitude. Para ser um bom ouvinte em 
relação ao idoso deve-se ouvir com o cérebro, com os olhos, com os ouvidos e com o coração.

Finalizando o presente trabalho, CAMPEDELLI ${ }^{3}$ ressaita que "quanto mais a enfermeira conhecer a respeito do seu paciente e estar disponível para ele, melhor será a assistência por ela prestada".

\section{CONCLUSÃO}

Considerando-se o aumento da população idosa em nossa sociedade, confirma-se a importância de estudos sobre as pessoas nessa faixa etária. Ao mesmo tempo, as relaçōes interpessoa is inerentes a todo ser humano, também faz-se imprescindível quando se trata de idosos.

O trabalho mostra que o relacionamento interpessoal entre o idoso e seus familiares depende de uma série de variáveis relacionadas a papel de cada um na estrutura familiar, e, principalmente, da visāo do próprio idoso sobre estes papéis sociais.

Os problemas de relacionamento apontados pelos idosos foram, em sua maioria, vinculados ao seu próprio comportamento, e as soluçōes identificadas foram em sua maioria direcionadas à satisfaçāo de suas próprias necessidades.

Os entrevistados percebem o processo de envelhecimento como: lei natural, acúmulo de experiências e ocorrência de alteraçōes fisicas.

$O$ conhecimento e a compreensão das características e especificidades próprias da pessoa na terceira idade e suas relaçōes familiares facilitarão a assistência de enfermagem ao idoso, seja no domicílio ou em instituiçōes.

COSTA, A. E.; MADEIRA, L. M. The interpersonnel relationship between the elder and his relatives. Rev. Eac. Enf. USP., v.28, n.1, p. 83-95, Apr. 1994.

This paper is an explorative - descriptive study trying to reach the followingving objectives: to know the interpersonnel relationship between the elder and his relatives and verify what is the elder's perception about the elderly process. The authorsirs interviewed 20 persons ( 10 men and 10 women) after 60 years of age. The results showedhowed probably will give some guidance for the nursing assistance to the elderly population.lation.

UNITERMS: Aged. Interpersonal relations.

\section{REFERÊNCIAS BIBLIOGRÁFICAS}

01. AGUIRRE, M.J.B.F. O ajustamento psicológico do idoso. In: UNIVERSIDADE DE SĀO PaULo. Reitoria. Problemas do idoso - um desafio social. Sảo Paulo, RUSP, 1984. p. 18-25. Cad.4. 
02. BERQUO, E.S.; LEITE. E.S. Algumas consideraçōes sobre a demografia da população idosa no Brasil. Ci.Cult. v.40, n.7, p.679-87, 1988.

03. CAMPEDELLI, M.C. Atuação da enfermagem em geriatria e gerontologia. Rev.Paul.Hosp.. v.31, n.9/10, p. 198-200, 1983.

04. COLLIERE, M.F. Invisible care and invisible women as health care-providers. Int.J.Nurs.Stud.,v.23, n.2, p.95-112, 1986

05. DREHER, B.B. Communication skills for working with elders. New York, Springer Publishing, 1987.

06. FraIMAN, A.P. Coisas da idade. 2ed. Sāo Paulo, Hermes Editora e Informaçāo, 1991. p.33.7.

07. HOGSTELL, M.O.; KASHKA, M. Staying healthy after 85. Geriatr.Nursing.,,v.10,n.1, p. 16-8. 1989.

08. JORDẢO-NETTO, A. Alternativas às limitaçóes sociais dos idosos. /Conferéncia apresentada na 7 Jornada Brasileira de Geriatria e Gerontologia. Rio de Janeiro, $1990 /$

09. Mitos e tabus na terceira idade. São Paulo, /Palestra apresentada na 22 Jornada Médico-Social da 3a. Idade. Campinas, 1989/.

10. Uma nova proposta para o estudo do envelhecimento humano. Sáo Paulo, SBGG-DGS, 1989./mimeografado/

11. LANGARICA, R. Aspectos espirituales y envejecimento. Enf.al Dia, v.16, n.6, p.23.6, 1991.

12. MONTGOMERY, C. What you can do for the confused elderly. Nursing, v.17,n.4, p.54-7, 1987.

13. MORAN, J.M. Elementos para pensar a comunicaçāo. In: SIBRACEn, 1, Ribeirảo Preto, 1988. Annis. Ribeirāo Preto, EERP/USP, 1988. p.66-94

14. MYERSCOUGH, P.R. Como comunicar com os doentes. Portugal, Publicaçōes Europa, 1989. p.125.

15. VIETTA, E.P.; CARVALHO, E.C. Processos de comunicaçāo à luz do marco conceitual para prática da enfermagem Social. In: SIBRACEn,1, Ribeirão Preto, 1988. Anais. Ribeiráo Preto, EERP/USP, 1988. p.338.49. 


\title{
ANEXO 1 \\ ROTEIRO DE ENTREVISTA
}

\author{
INICIAIS: $\quad$ ANO DE NASCIMENTO: \\ SEXO: GRAU DE PARANTESCO COM O PROFESSOR: \\ GRAU DE INSTRUÇĀO: \\ COM QUEM RESIDE: \\ QUESTÖES
}

1. Com quem o Sr(a) se dá melhor em sua família? Por quê? (grau de parentesco, se residem juntos ou nāo, faixa etária).

2. Com quem o $\operatorname{Sr}(a)$ se dá pior em sua familia? Por quê?

3. Como o $\mathrm{Sr}(a)$ gostaria que fosse o relacionamento entre o $\mathrm{Sr}(a)$ e sua familia?

4. O Sr(a) acha que pessoa idosa tem dificuldades de comunicar-se com pessoas de sua família? Caso afirmativo, quais são as dificuldades.

5. Para o $\operatorname{Sr}(a)$ o que é envelhecer?

Outras declaraçōes. 


\section{ANEXO II}

QUADRO 1 - Caracterização dos Idosos, segundo o Sexo e Idade.

Belo Horizonte, 1992.

\begin{tabular}{|c|c|c|c|c|c|c|c|}
\hline \multirow[t]{2}{*}{ IDADE } & \multirow[t]{2}{*}{ SEXO } & \multicolumn{2}{|c|}{ MAS } & \multicolumn{2}{|c|}{ FEMIN. } & \multicolumn{2}{|c|}{ TOTAL } \\
\hline & & $N^{2}$ & $q$ & $\mathrm{~N}^{2}$ & $q_{0}$ & $\mathrm{~N}^{2}$ & $\%$ \\
\hline $60-1$ & 65 & 2 & 20,0 & 5 & 50,0 & 7 & 35,0 \\
\hline $65-1$ & 70 & 4 & 40,0 & 4 & 40,0 & 8 & 40,0 \\
\hline $70-1$ & 75 & 3 & 30,0 & 1 & 10,0 & 4 & 20,0 \\
\hline $75-1$ & 80 & - & - & - & - & - & - \\
\hline 80 & & 1 & 10,0 & . & - & 1 & 5,0 \\
\hline TOTAL & & 10 & 100,0 & 10 & 100,0 & 20 & 100,0 \\
\hline
\end{tabular}

QUADRO 2 - Caracterizaçīo dos Idosos, segundo Escolaridade e Sexo.

Belo Horizonte, 1992.

\begin{tabular}{|c|c|c|c|c|c|c|}
\hline \multicolumn{7}{|c|}{ ESCOLARIDADE } \\
\hline \multicolumn{3}{|c|}{ SEXO } & \multicolumn{2}{|c|}{ FEMIN. } & & TOTAL \\
\hline & $N^{2}$ & $\%$ & $\mathrm{~N}^{2}$ & $\%$ & $\mathrm{~N}^{2}$ & $\%$ \\
\hline Primário & 5 & 50,0 & 5 & 50,0 & 10 & $\mathbf{6 0 , 0}$ \\
\hline Ginasial & 1 & 10.0 & 3 & 30,0 & 4 & 20,0 \\
\hline Normal & - & - & 2 & 20,0 & 2 & 10,0 \\
\hline Contabilidade & 1 & 10,0 & - & - & 1 & 5,0 \\
\hline Diroito & 1 & 10,0 & - & - & 1 & 6,0 \\
\hline Engenharia & 1 & 10,0 & - & - & 1 & 6,0 \\
\hline Modicina & 1 & 10,0 &. & - & 1 & 5,0 \\
\hline TOTAL & 10 & 100,0 & 10 & 100,0 & 20 & 100,0 \\
\hline
\end{tabular}

